\title{
One-Step Method for Endothelial Cell Isolation from Large Human Blood Vessels Using Fibrin Glue
}

\author{
Ellen B. M. van Leeuwen, Grietje Molema, Koert P. de Jong, \\ Marja J. A. van Luyn, Freark Dijk, Maarten J. H. Slooff, Marcel H. J. Ruiters, and \\ Jan van der Meer
}

Department of Haemostasis, Thrombosis, and Rheology (EBML, JM), Pathology and Laboratory Medicine (EBML, GM, MJAL, MJHS, MHJR), Surgery (KPJ), Cell Biology and Electron Microscopy (FD), University of Groningen and University Hospital, Groningen, The Netherlands

$I$ solation of endothelial cells (EC) from large human blood vessels obtained from multi-organ donors cannot be performed as described for human umbilical cords (Jaffe et al, 1973) because of the availability of only small segments with side branches and incisions. We isolated EC from segments of human iliac arteries and veins with collagenase while the adventitia side of the vessels was attached to the culture dish with fibrin glue. This prevented the collagenase from making contact with the adventitia side, resulting in a high yield of EC with minimized contamination of cells from nonendothelial origin.

Iliac arteries and veins from multiorgan donors were stored in cold preservation solution (UW) until 7 days after liver transplantation. Before isolation of EC, a tissue sample of $100 \mathrm{~mm}^{2}$ was removed for scanning electron microscopy, showing varying EC-coverage and quality as described previously (van Leeuwen et al, 2000). Multiplication of the total intimal surface and the percentage of surface covered with EC resulted in the actual EC-surface available for isolation (Table 1).

For EC isolation, the blood vessels were prepared by removing connective tissue, fat, and lateral vessels. After opening each vessel lengthwise, the adventitia side was dried with sterile gauze. One layer of the gauze was left on the adventitia side and cut off around the vessel. Combining Tissucol and thrombin $500 \mathrm{lU} / \mathrm{ml}$ (one $\mathrm{ml}$ each for $10 \mathrm{~cm}^{2}$ ) from the Tissucol Kit (Immuno B.V., Raamsdonksveer, The Netherlands) results in fibrin formation within 30 seconds. The thrombin solution was applied to the bottom of a culture dish and the Tissucol solution to the gauze on the adventitia side of the blood vessel. After placing the blood vessel in the culture dish with the adventitia

Received March 20, 2000.

Address reprint requests to: Dr. E.B.M. van Leeuwen, Department of Pathology, University Hospital Groningen, PO Box 30.001, 9700 RB Groningen, The Netherlands. Fax: 050363 2510; E-mail: e.van.leeuwen@path.azg.nl side down, fibrin was formed. After 3 minutes, a period required to obtain sufficient fibrin strength, $25 \mathrm{ml}$ of a $0.2 \mathrm{mg} / \mathrm{ml}$ collagenase solution (Sigma Chemical Company, St. Louis, Missouri) was applied on top of the intimal surface. After 30 minutes at $37{ }^{\circ} \mathrm{C}$, the collagenase solution was removed from the blood vessel and added to $25 \mathrm{ml}$ of culture medium as routinely used for human umbilical vein endothelial cell (HUVEC) culture. This mixture was filtered through a sterile $100 \mu \mathrm{m}$ nylon filter (vs-monodur 100), centrifuged, resuspended in $2 \mathrm{ml}$ of culture medium, seeded in a gelatin-coated cluster plate, and cultured as described for HUVEC (van Leeuwen et al, 1999). When the cells reached confluence in 6 well cluster plates, cytospots were prepared, fixed for 10 minutes in cold acetone:glacial acetic acid (volume 4:1), and stained using peroxidase-conjugated rabbit anti-human von Willebrand Factor (vWF; DAKO, Glostrup, Denmark), mouse anti-human CD31 (DAKO), peroxidaseconjugated rabbit anti-mouse immunoglobulin (DAKO), and 3-amino-9-ethylcarbazole (Sigma).

In general, treatment of the vessels with chymotrypsin did not result in a significant EC-yield. When collagenase was used, a higher EC yield and purity was obtained (Table 1). Reduction of incubation time from 60 to 30 minutes to prevent possible damage to the isolated cells did not affect EC yield and purity. No correlation was observed between the actual EC surface $\left(\mathrm{mm}^{2}\right)$, the EC quality (score 1-10), and the purity (CD31, vWF) of the EC cultures (Table 1). This indicates that viability of the EC is high even when coverage and morphologic quality are low.

When isolation yielded a high number of cells, represented by a short culture period to reaching confluence ( $<18$ days), the cells were $>98 \%$ CD31 positive (Table 1). When the cell yield was low $(>18$ days), the cultures were less pure, most likely because contaminating cells grew faster than EC. Two exceptions to this rule were observed. In cultures V3 and V13 (Table 1), outgrowth of one EC cluster resulted in 

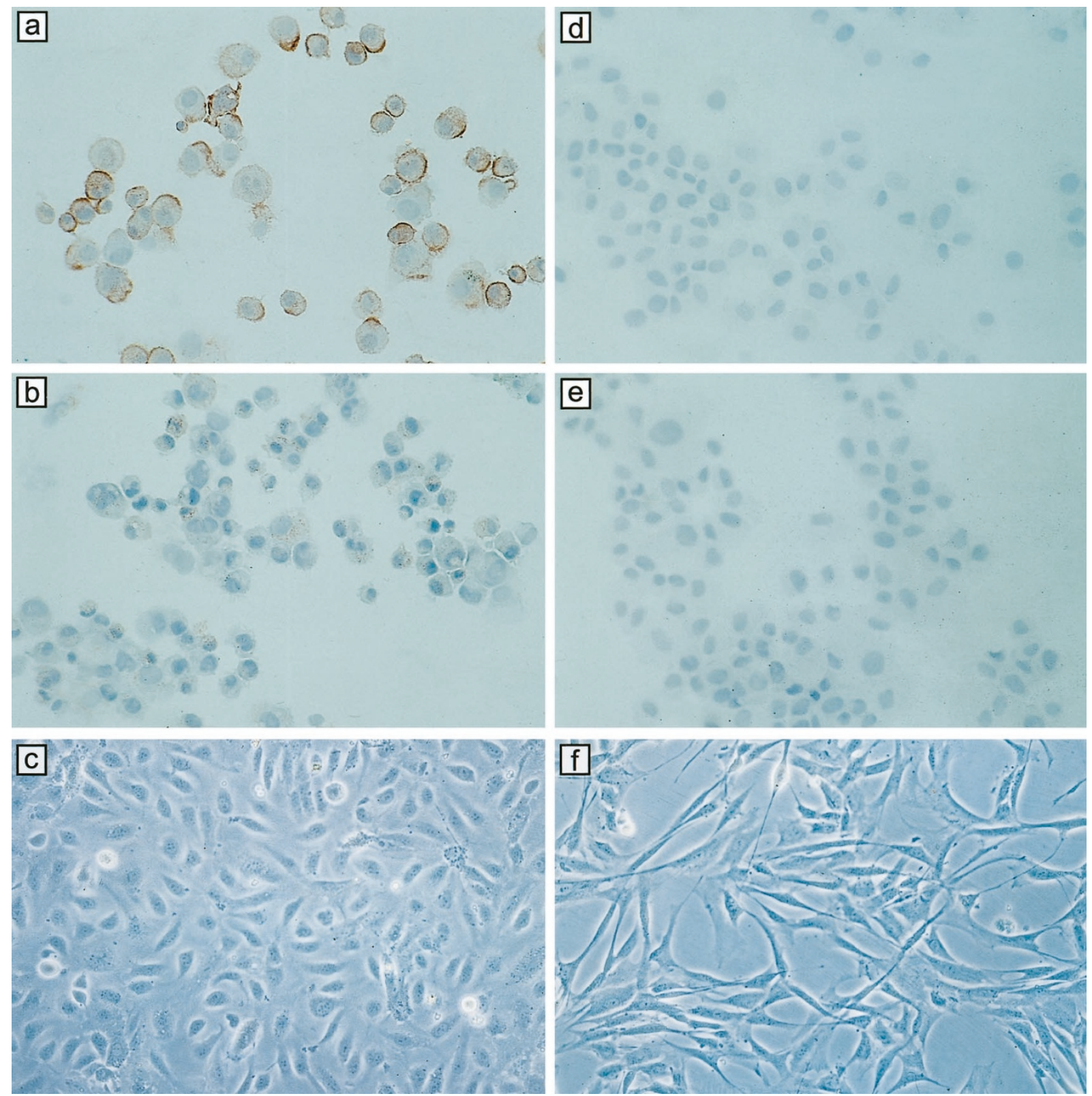

\section{Figure 1.}

Endothelial cells isolated from artery A15 were $>98 \%$ CD31 (a) and 40\%-60\% vWF positive $(b)$ and exerted typical EC cobblestone morphology $(c)$. Cells isolated from artery A16 are not of endothelial origin, possibly because of insufficient masking of the adventitia side by the fibrin glue. In agreement with the absence of EC markers, CD31 (d) and VWF $(e)$ the morphology was clearly different $(f)$.

high numbers of CD31 positive cells, even when time in culture was longer than 1 month. This was most likely caused by the fact that these cultures were derived from one single EC without the presence of contaminating cells.

The percentage of CD31 positive cells was always higher than the percentage of VWF positive cells. With longer time in culture, the number of vWF positive EC decreased (Table 1). This can be explained by EC senescence during which vWF is lost (Johnson et al, 1992). The percentage of VWF positive cells in arterial cultures was lower than that in veins, and this can also be explained by senescence, because the primary cell isolate yield from arteries was lower than that from veins. Human iliac EC showed patterns of CD31 and vWF (Fig. 1) comparable with HUVEC.

In conclusion, this one-step enzymatic technique allows isolation of EC from various human vessels with minimal contamination by cells of nonendothelial origin. This method will increase the availability of EC from different human blood vessels for in vitro research.

\section{Acknowledgements}

We thank Immuno B.V. for providing the Tissucol Kit and Rik Wijmans for his expert advice on the application of fibrin glue. The electron microscopic part of this study was financially supported by the "J.K. de Cock- 
Table 1. Overview of Endothelial Cell Isolation from Iliac Vessels

\begin{tabular}{|c|c|c|c|c|c|c|}
\hline $\begin{array}{c}\text { Blood } \\
\text { Vessel }^{a}\end{array}$ & $\begin{array}{l}\text { EC surface } \\
\qquad\left(\mathrm{mm}^{2}\right)\end{array}$ & $\begin{array}{l}\text { EC quality } \\
(1-10)\end{array}$ & $\begin{array}{l}\text { Days in } \\
\text { Culture }\end{array}$ & $\begin{array}{l}\text { Total Number } \\
\text { of Cells }\left(10^{6}\right)\end{array}$ & $\begin{array}{c}\% \text { vWF } \\
\text { Pos. Cells }{ }^{b}\end{array}$ & $\begin{array}{c}\% \text { CD31 } \\
\text { Pos. Cells }{ }^{b}\end{array}$ \\
\hline \multicolumn{7}{|c|}{ Chymotrypsin for 60 min. } \\
\hline V1 & 410 & 6 & 18 & 0.30 & \pm & + \\
\hline V5 & 840 & 7 & 19 & 0.27 & + & +++ \\
\hline V2 & 600 & 6 & 20 & 0.25 & - & \pm \\
\hline V9 & 840 & 8 & 29 & 0.15 & - & \pm \\
\hline V4 & 10 & 2 & 36 & none & & \\
\hline V3 & n.d. & 7 & $49^{c}$ & 0.35 & ++ & +++++ \\
\hline A4 & 70 & 4 & 13 & 0.45 & ++++ & +++++ \\
\hline A1 & 120 & 5 & 18 & 0.30 & \pm & \pm \\
\hline $\mathrm{A} 2$ & 90 & 3 & 20 & 0.14 & - & + \\
\hline \multicolumn{7}{|c|}{ Collagenase for $60 \mathrm{~min}$. } \\
\hline V8 & 520 & 8 & 5 & 0.88 & +++++ & +++++ \\
\hline V9 & 1260 & 8 & 13 & 0.90 & +++++ & +++++ \\
\hline V10 & 1050 & 7 & 26 & none & & \\
\hline \multicolumn{7}{|c|}{ Collagenase for $30 \mathrm{~min}$. } \\
\hline V12 & 650 & 7 & 10 & 0.55 & ++++ & +++++ \\
\hline V16 & 550 & 4 & 12 & 0.80 & ++++ & +++++ \\
\hline V14 & 1260 & 6 & 14 & 0.50 & +++ & +++++ \\
\hline V13 & 140 & 2 & $35^{c}$ & 0.45 & ++++ & +++++ \\
\hline A15 & 420 & 3 & 5 & 0.40 & +++ & +++++ \\
\hline A14 & 400 & 5 & 14 & 0.30 & + & +++++ \\
\hline A11 & 500 & 7 & 17 & 0.45 & + & +++++ \\
\hline A12 & 440 & 6 & 18 & 0.55 & + & +++++ \\
\hline A16 & 420 & 7 & 21 & 0.45 & - & - \\
\hline A13 & 650 & 8 & 35 & none & & \\
\hline
\end{tabular}

Data are sorted for days in culture.

${ }^{a}$ Veins $(\mathrm{V})$ and arteries (A) are numbered in order of isolation.

${ }^{b}$ The percentage of VWF and CD3 positive cells was scored as follows: - (negative), $\pm(<1 \%),+(1-20 \%),++(20-40 \%),+++(40-60 \%),++++$ $(60-80 \%),+++++(80-100 \%)$.

${ }^{c}$ Outgrowth of one endothelial cell cluster, probably derived from one single isolated endothelial cell.

n.d. $=$ not determined.

stichting" (Grant No. 98-23). Dr. G. Molema is a fellow of the Royal Netherlands Academy of Arts and Sciences (KNAW).

\section{References}

Jaffe EA, Nachman RL, Becker CG, and Minick CR (1973). Culture of human endothelial cells derived from umbilical veins: Identification by morphologic and immunologic criteria. J Clin Invest 52:2745-2756.

Johnson TE, Umbenhauer DR, Hill R, Bradt C, Mueller SN, Levine EM, and Nichols WW (1992). Karyotypic and phenotypic changes during in vitro aging of human endothelial cells. J Cell Physiol 150:17-27. van Leeuwen EBM, Molema G, van Luyn MJA, de Jong KP, Dijk F, Slooff MJH, Ruiters MHJ, and van der Meer $J$ (2000). Scanning electron microscopic analysis of endothelial cell coverage and quality in large vessels from multi-organ donors: Effects of preservation on endothelial cell integrity. Clin Transplant 14:246-251.

van Leeuwen EBM, van der Veen AY, Hoekstra D, Engberts JBFN, Halie MR, van der Meer J, and Ruiters MHJ (1999). Transfection of small numbers of human endothelial cells by electroporation and synthetic amphiphiles. Eur J Vasc Endovasc Surg 17:9-14. 